Article

\title{
Longitudinal Compressive Property of Three-Dimensional Four-Step Braided Composites after Cyclic Hygrothermal Aging under High Strain Rates
}

\author{
Kailong $\mathrm{Xu} \oplus$, Wei Chen ${ }^{\circledR}$, Lulu Liu *, Gang Luo and Zhenhua Zhao \\ Jiangsu Province Key Laboratory of Aerospace Power System, College of Energy and Power Engineering, \\ Nanjing University of Aeronautics and Astronautics, Nanjing 210016, China; xukailong@nuaa.edu.cn (K.X.); \\ chenwei@nuaa.edu.cn (W.C.); mevislab@nuaa.edu.cn (G.L.); zhaozhenhua@nuaa.edu.cn (Z.Z.) \\ * Correspondence: liululu@nuaa.edu.cn
}

Received: 12 February 2020; Accepted: 11 March 2020; Published: 18 March 2020

\begin{abstract}
The longitudinal compressive behavior of the three-dimensional four-step braided composites after cyclic hygrothermal aging was investigated using a split Hopkinson pressure bar (SHPB) apparatus under high strain rates (1100 1250 s${ }^{-1}, 1400 \sim 1600 \mathrm{~s}^{-1}, 1700 \sim 1850 \mathrm{~s}^{-1}$, respectively). The SEM micrographs were examined to the damage evolution of the composites after cyclic hygrothermal aging. A high-speed camera was employed to capture the progressive damage process for the composites. The results indicate that the saturated moisture absorption of the composites was not reached during the whole 210 cyclic hygrothermal aging days. The composites mainly underwent epoxy hydrolysis and interfaces debonding during continuous cyclic hygrothermal aging time. The peak stress of the composites still behaved as a strain rate effect after different cyclic hygrothermal aging days, but the dynamic stiffness modulus clearly had no specific regularity. In addition, the peak stress and the dynamic stiffness modulus of the composites after 210 cyclic hygrothermal aging days almost decreased by half when subjected to longitudinal compression.
\end{abstract}

Keywords: cyclic hygrothermal aging; high strain rates; braided composites; compressive property

\section{Introduction}

Fiber reinforced composites (FRC) are widely applied in many engineering applications, such as aerospace, wind power and energy, due to their excellent mechanical properties in recent decades [1-3]. In particular, the laminated composites are more commonly used in aerospace. However, the traditional laminated composites have the disadvantages of relatively low fracture toughness in plane and delamination through thickness. In the recent decade, three-dimensional (3D) textile composites, e.g., weaving, knitting and braiding, have received extensive attention thanks to their excellent anti-delamination characteristics. Specifically, the 3D braided composites were generally recognized as the most promising textile composites, due to their excellent anti-delamination properties [4-6]. Composite structure in aircraft applications may be subjected to a large number of dynamic loads, e.g., bird strike, blade out and unexpected fragment impact $[7,8]$. Therefore, it is necessary and meaningful to understand their dynamic mechanical properties at high strain rates, to guide the design of composite structure that will be used under dynamic loadings in engineering applications.

Many efforts have been committed on the dynamic mechanical behavior of the 3D textile composites in recent years. Gu and $\mathrm{Xu}$ [9] conducted the ballistic perforation tests of the 3D four-step braided Twaron/epoxy composites, and adopted a "Fiber inclination model" to decompose 3D braided composites to geometrical modeling in FEM, proving that the analysis scheme in microstructures 
can work. Sun et al. [10-12] studied in-plane, out-plane compressive and uniaxial tensile mechanical behavior of the 3D four-step braided composites through a series of experiments at different strain rates and discussed its failure modes. The results revealed that the 3D braided composite is sensitive to strain rate and the higher strain rate, the higher failure stress and compressive stiffness. Walter et al. [13] presented dynamic indentation and small caliber ballistic impact tests for the 3D glass fiber composites; they concluded that the delamination damage at high strain rates was still a dominant failure mode in the 3D woven composites. Zhang et al. [14] reported the compressive mechanical performance and damage mode at quasi-static and high strain rates, based on a meso-structure model of the 3D four-step braided composites; the results proved the validity of meso-structure FEM model. Recently, Tan [15] experimentally studied dynamic compressive response of the 3D four-step braided composites in three directions (longitudinal, transverse and thickness, respectively), and the experiments of dynamic compressive tests revealed that with increasing the strain rate of composites, the compressive stiffness and failure stress both increased.

Most research on the above papers was focused on investigating the mechanical properties on compressive behavior in room temperature, not considering the impact of environment. However, composites structure, usually subject to long-term hygrothermal exposures during their service life, such as the aero-engine fan blade with carbon fiber reinforced polymer material, operating in the temperature and humidity environment, is continuously exposed to a hygrothermal environment. Epoxy in composites, as a typical thermoset resin, will absorb the moisture, inducing swelling and plasticization [16-18]. Composites' mechanical advantages such as stiffness and strength will significantly be affected because of hygrothermal aging [19-22]. Yilmaz and Sinmazcelik [23] investigated the effects of moisture on thermal and mechanical properties and the moisture absorption of glass-fiber/polyetherimide (PEI) laminated composites, and the laminated composites were exposed to hydrothermal aging environment under two different temperatures and high moisture rates. The hydrothermal aging laminates comprised a large number of moisture, causing a decrease in the glass transition temperature and degradation in mechanical properties. Sun et al. [24] studied the hygrothermal aging properties of carbon fiber/bismaleimide (BMI) composites, and measured the water diffusivity through the three wet-dry cycles of BMI resin, reinforced with unidirectional carbon fiber CCF300/QY9511 composites. The results showed that the re-absorption of CCF300/QY9511 composites exhibit a higher amplitude of diffusivity but a lower saturated moisture content. Li et al. [25] extensively investigated the low velocity impact tests of laminated composites in an ambient hygrothermal environment, and the unidirectional and crossply glass fiber reinforced plastic (GFRP) laminates were placed in a conditioning chamber for a maximum of eight moisture cycles from 50 to $100{ }^{\circ} \mathrm{C}$. The impact loading decreases and the deflection increases with cycling moisture levels. Liotier et al. [26] analyzed the micro-cracking of polymer matrix composites through using multiaxial multi-ply stitched carbon preforms, subjected to purely cyclic hygrothermal loadings. The specific cracks occurred within the resin transverse channels sur-rounding the stitches, showing that hygrothermal damage is different to that caused by the mechanical loadings [27]. Patel [28] designed a $24 \mathrm{~h}$ cyclic hygrothermal aging spectrum, containing cyclical variations between temperature and moisture, which aimed to simulate a mission environment for an advanced subsonic aircraft. Durability research on the hygrothermal aging material system was carried out. Experiments showed that the initial and residual tensile properties after hygrothermal aging were almost unaffected by hygrothermal aging. However, residual strength and dynamic stiffness were significantly decreased at high temperature. Recently, Liu et al. [29] experimentally investigated the high velocity impact performance of the T700/TDE85 carbon/epoxy composites after cyclic hygrothermal aging in an environmental chamber at a constant temperature and humidity $\left(70{ }^{\circ} \mathrm{C}, 95 \% \mathrm{RH}\right)$ for the first time. They found that the ballistic limit of a carbon/epoxy composite decreases after long-time hygrothermal aging. Zhang et al. [30] reported the thermal aging on the compressive behavior of pure epoxy and 3D braided composites, the epoxy, and the 3D braided composites were aged in air for $1,2,4,8$, and 16 days at $180^{\circ} \mathrm{C}$. The experiments and the micrograph of samples by using the scanning electron microscope (SEM) revealed that epoxy initiated degradation in 
regions close to the surface layer, and the compressive behavior degradation was mainly from interface degradation and crack propagation after high temperature aging. Song [31] carried out tensile tests of 3D four-step braided composite after heat accelerated aging under 150 and $180^{\circ} \mathrm{C}$ for 60,120 and 180 h. After aging, they found that the structure of braided composites still kept integrity, and the tensile performance degraded less. To our knowledge, much research has been focused on the mechanical properties considering the hygrothermal aging effects of resin-based laminated composites except the above two papers, with respect to 3D braided composites. There are even fewer articles on the 3D braided composite after cyclic hygrothermal aging. Therefore, it is of a certain significance to research the 3D braided composite after cyclic hygrothermal aging.

The objective of this paper is to investigate the dynamic compressive mechanical properties of the 3D four-step braided composites along the longitudinal direction after cyclic hygrothermal aging. All of the research in this paper can be divided into three stages: first, identify the moisture absorption of 3D four-step braided composites after cyclic hygrothermal aging, observe morphology evolution of the cross section for the 3D four-step braided composite by using SEM; then, quantify the dynamic mechanical property degradation caused by the cyclic hygrothermal aging effect; finally, evaluate the cyclic hygrothermal aging effects on the dynamic compressive mechanical performance of 3D four-step braided composites.

In this work, the 3D four-step carbon/epoxy (T700-12K/TDE-86) braided composites were exposed to cyclic hygrothermal environment. An accelerated hygrothermal aging spectrum for a military aircraft was applied. SEM was used to observe composites' morphology changes at different cyclic hygrothermal aging days. A split Hopkinson pressure bar (SHPB) was employed to evaluate the dynamic compressive mechanical property along the longitudinal direction of the 3D four-step braided composites at various cyclic hygrothermal aging days.

\section{Experimentation}

\subsection{Material and Specimens}

The 3D performs of composites in this paper were manufactured by four-step $1 \times 1$ method, with 12K T700 carbon fibers (made by Toray Industries) as braiding yarns. The schematic of the four-step 1 $\times 1$ braiding process can be found at Figure 1. During the braiding process, a perform for braiding was hung above the braided machine bed, on which yarn carriers were arranged in a preset style, in order to satisfy the cross-section shape of the braiding perform. More specifically, the first step involved the motion of yarn carriers in alternate rows, and the second step involved the motion of yarn carriers in alternate columns. The motion of yarn carriers in the third and fourth steps were similar to the first and second steps, respectively, except for the motion compared with the first and second steps in the opposite direction. The epoxy resin (TDE-86, from Tianjin Jingdong chemical composites Co., LTD of China, the epoxy value $\geq 0.90 \pm 0.02$ ) was injected into the performs through vacuum assisted resin transform modeling (VARTM); the fiber volume fraction in the 3D four-step braided plate is $60 \pm 2 \%$. The specimens for measuring moisture absorption were cut from the nominal dimension of $380 \mathrm{~mm}$ (longitudinal direction) $\times 180 \mathrm{~mm}$ (transverse direction) $\times 4 \mathrm{~mm}$ (thickness direction) plate, with a braiding angle of $20^{\circ}$. Finally, the specimens were cut in the shape of $50 \mathrm{~mm} \times 50 \mathrm{~mm} \times 4 \mathrm{~mm}$, as shown in Figure 2, according to the ASTM DD5229/D5299M standard [32]. As for the dimensions of specimens for SHPB tests is $10 \mathrm{~mm} \times 10 \mathrm{~mm} \times 10 \mathrm{~mm}$, as shown Figure 3, further details about manufacturing or other related information can be found in our previous work [15]. 


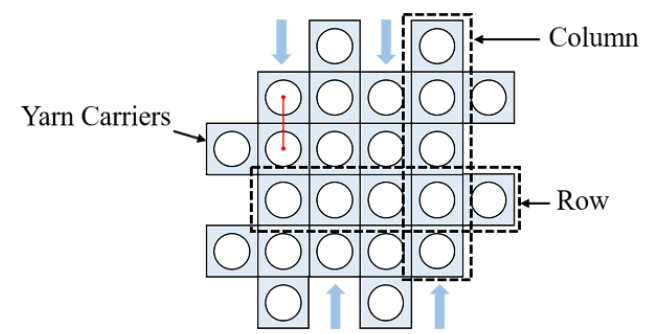

(a) First step

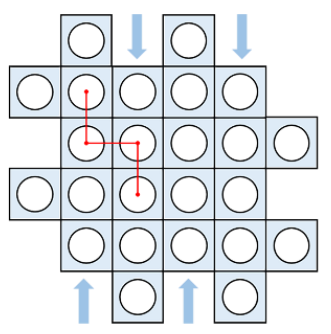

(c) Third step

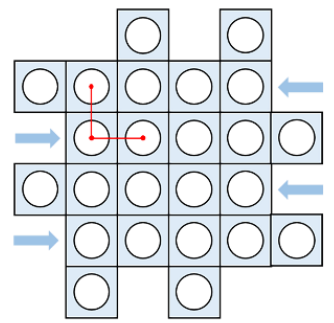

(b) Second step

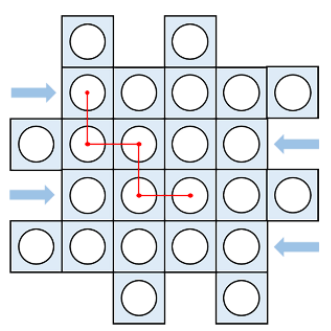

(d) Fourth step

Figure 1. Schematic of four-step $1 \times 1$ braiding process, (a) First step, (b) Second step, (c)Third step, (d) Fourth step.

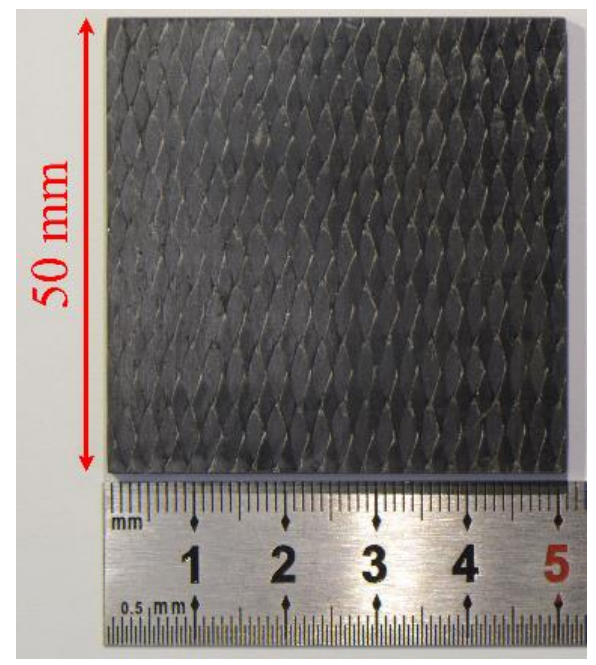

Figure 2. Specimen of 3D four-step braided composite for measuring moisture absorption.
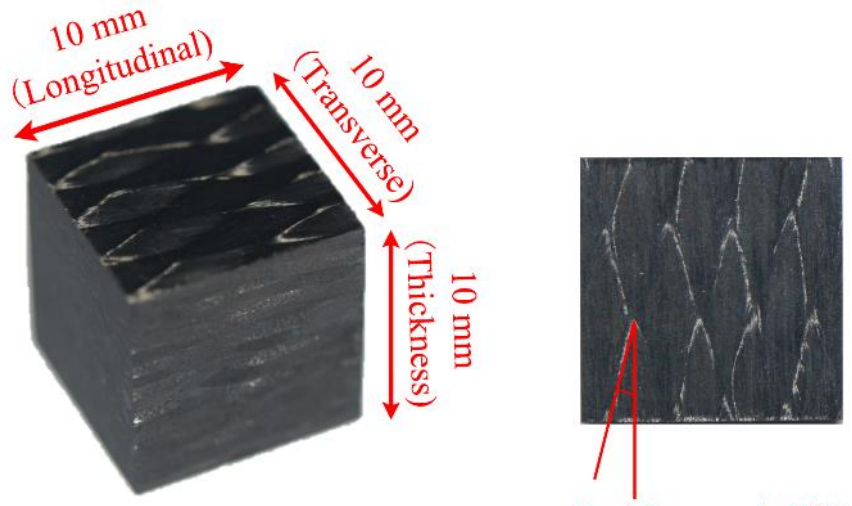

Braiding angle $20^{\circ}$

Figure 3. Specimen of 3D four-step braided composite for SHPB tests. 


\subsection{Hygrothermal Cycling}

Military aircrafts experience, during service, the following; pre-flight time of the aircraft on the ground, the takeoff, the combat air patrols, and finally, the landing [33]. During the flight cycle, the composites on aircrafts experience temperature and humidity circulations alternately, therefore, it is absolutely necessary to investigate the mechanical performance of composites in-service, under the specific hygrothermal aging condition.

The hygrothermal cycling tests took place in the LRHS-101D-LJS high and low temperature chamber, alternately. Before placing the specimens into the chamber, the specimens were all dried at $70{ }^{\circ} \mathrm{C}$, until the variation of weight was just under $0.02 \%$ [32]. An accelerated hygrothermal aging spectrum first proposed by $\mathrm{Li}$ [34] was employed. Likewise, we investigated the inter-laminar shear property and high-velocity impact resistance of carbon fiber-reinforced epoxy polymer (CFRP) composites after cyclic hygrothermal aging for the first time, by the same aging spectrum as in our previous work [35]. Figure 4 illustrates the set points prescribed temperature and humidity profile of one hygrothermal aging cycling process, in which the lowest temperature is $70{ }^{\circ} \mathrm{C}$, and the highest temperature is $110^{\circ} \mathrm{C}$. A hygrothermal aging cycling process continues for $1440 \mathrm{~min}$ (one day), and the highest temperature is $110{ }^{\circ} \mathrm{C}$ lower than the glass transition temperature of the epoxy resin; more details about description of this hygrothermal aging spectrum can be found in our previous works [35], which are not repeated here. The 14 cycles (same as 14 days) of accelerated hygrothermal aging represent the effects of natural aging for one year at the same environmental state.

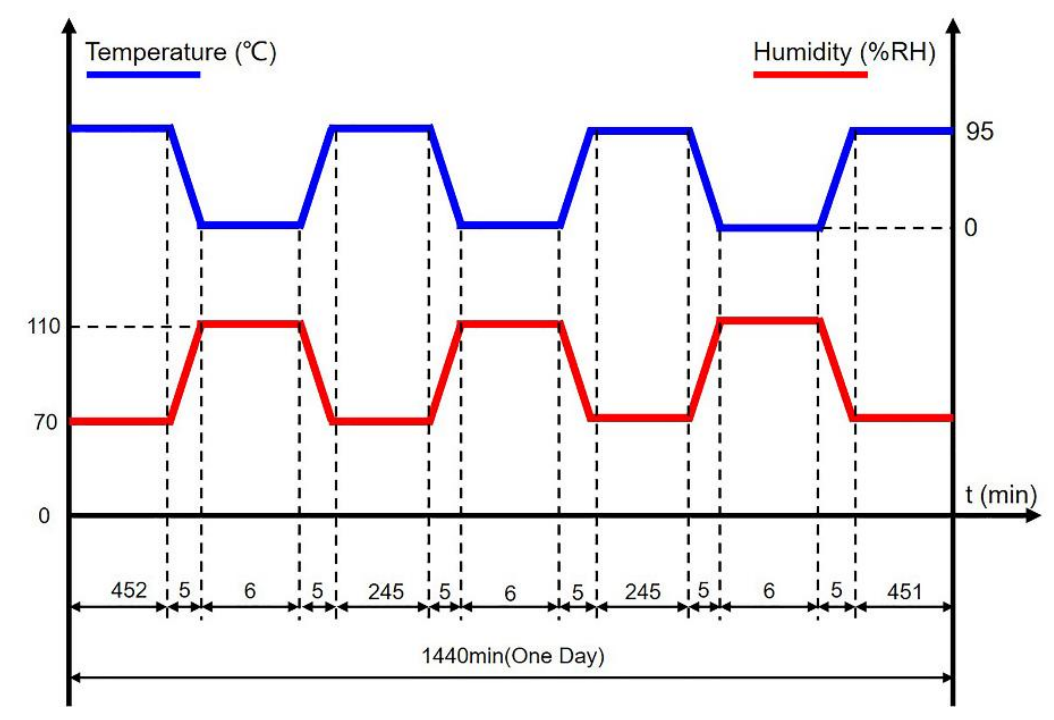

Figure 4. Accelerated hygrothermal aging spectrum for the 3D braided composites.

Five specimens for moisture absorption were employed for the moisture absorption tests. The weight of these specimens were measured at intervals of $24 \mathrm{~h}$ (one hygrothermal aging cycle) by using an analytical balance (accuracy $0.1 \mathrm{mg}$ ). The weights obtained from the five specimens were averaged. All specimens for SHPB tests were divided into four groups, aged for 14, 70, 140, 210 days in the hygrothermal chamber, respectively. When the target aging time reached, the specimens were cooled down to room temperature and put into sealed plastic bags to prevent moisture absorption again.

\subsection{Microscopy Observation}

A scanning electron microscope (SEM, JapanElectron Optics Laboratory Co. Ltd.,Tokyo, Japan) was used to observe the morphologies of specimens after cyclic hygrothermal aging. 


\subsection{SHPB Tests}

The SHPB apparatus [36] has been widely used to investigate the dynamic behaviors of materials at high strain rate $\left(10^{2}-10^{4} \mathrm{~s}^{-1}\right)$. The SHPB apparatus consists of a strike bar, an incident bar, a transmission bar, an absorbing bar and a shock absorber. Figure 5 shows a schematic of SHPB apparatus for dynamic compressive tests. In this study, all bars have diameters of $14.5 \mathrm{~mm}$, and the incident bar and transmission bar both have a length of $1.5 \mathrm{~m}$. The striker bar is fired from the gas gun system, and then the striker bar impacts the free end of the incident bar. Upon impact, a longitudinal elastic compressive stress wave is created, which propagates along the incident bar toward the incident bar/specimen interface; once the compressive stress wave has reached the incident bar/specimen interface, and the compressive has been divided into two parts: one part is reflected back into the incident bar as a tensile stress wave, and the other part of the stress wave which is not reflected is transmitted into the specimen, and the wave that is transmitted into specimen propagates reaches the specimen/transmission bar interface along the loading direction of the specimen. When the wave reaches the interface between the transmission bar and the specimen, one part of the stress wave is reflected into the specimen, and the other part of the stress wave is transmitted into the transmission bar. Finally, the transmission bar along its axis displaces until the other end of it reaches the absorbing bar, and the stress wave is absorbed by the shock absorber. The stress wave within the specimen undergoes a complex reverberation, until the dynamic compressive strength of the specimen is reached. It should be noted that the dynamic deformation of $3 \mathrm{D}$ braided composites is in a longitudinal direction; more specific details are shown in Figure 13.

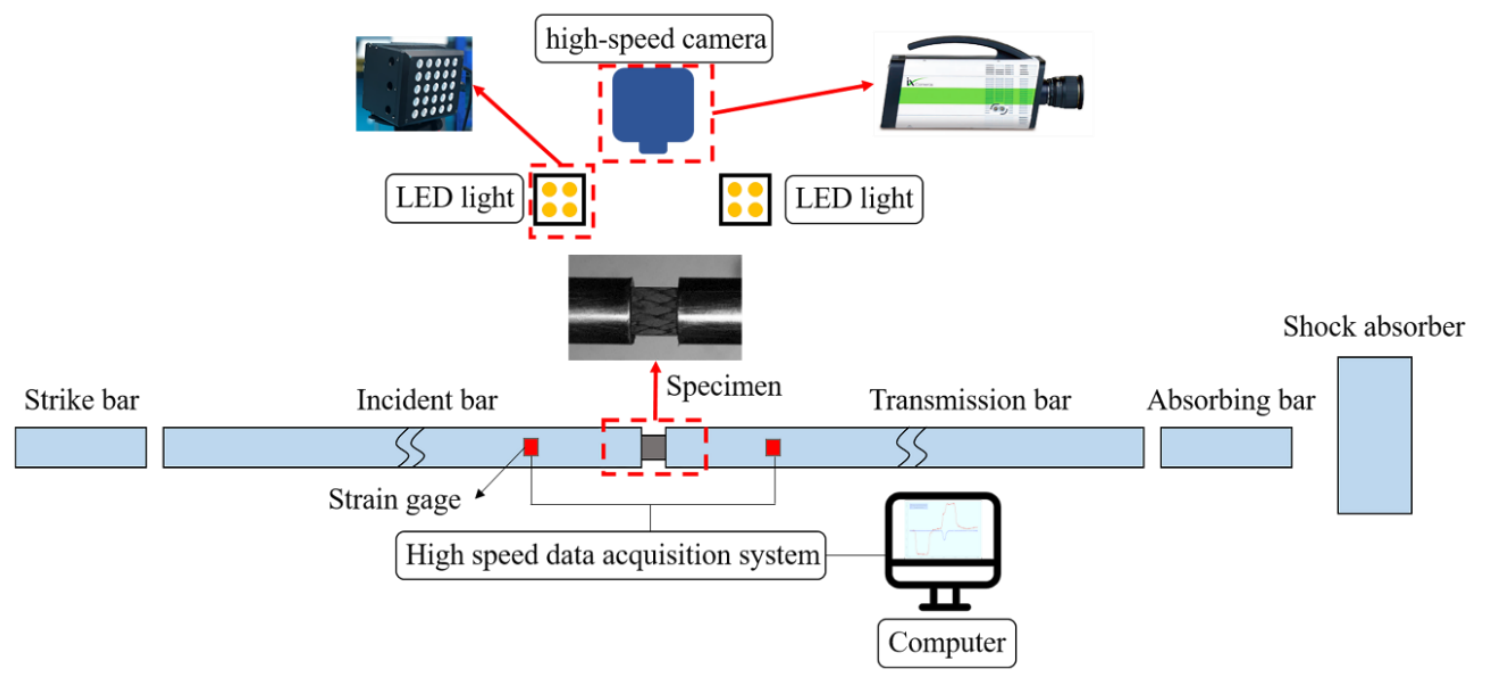

Figure 5. Schematic of SHPB(split Hopkinson pressure bar)apparatus.

During dynamic compressive tests, two strain gauges, which were mounted diametrically opposite to each other on the incident bar and transmission bar to cancel any bending strains, were employed to measure the incident, reflect and transmit signals, respectively. The data were captured by using a high-speed data acquisition card, employing a sampling rate of $1 \mathrm{MHz}$. A high-speed camera was employed to capture the deformation and damage evolution process during impact. In this paper, we chose a resolution of $1792 \times 448$, and the sampling frequency was $20000 \mathrm{fps}$. Besides, two LED lights were placed on both sides of the high-speed camera to enhance the light on the specimen, in order to obtain clearer photos.

In this study, the strain signals from strain gauges were analyzed based on one-dimensional wave propagation assumption. The stress $\left(\sigma_{\mathrm{s}}\right)$, strain $\left(\varepsilon_{\mathrm{s}}\right)$ and strain rate $\left(\dot{\varepsilon}_{\mathrm{s}}\right)$ could be obtained through the following equations, respectively [37]: 


$$
\begin{gathered}
\sigma_{\mathrm{S}}(\mathrm{t})=\frac{\mathrm{A}_{0}}{\mathrm{~A}_{\mathrm{s}}} \mathrm{E}_{0} \varepsilon_{\mathrm{T}}(\mathrm{t}), \\
\varepsilon_{\mathrm{S}}(\mathrm{t})=-2 \frac{\mathrm{C}_{0}}{1_{\mathrm{S}}} \int_{0}^{\mathrm{t}}\left(\varepsilon_{\mathrm{I}}(\mathrm{t})-\varepsilon_{\mathrm{T}}(\mathrm{t})\right) \mathrm{dt}, \\
\dot{\varepsilon}_{\mathrm{S}}(\mathrm{t})=-2 \frac{\mathrm{C}_{0}}{\mathrm{l}_{\mathrm{S}}}\left(\varepsilon_{\mathrm{I}}(\mathrm{t})-\varepsilon_{\mathrm{T}}(\mathrm{t})\right),
\end{gathered}
$$

where $C_{0}=\sqrt{E_{0} / \rho_{0}}$ is the longitudinal stress wave velocity in the bar, $E_{0}$ is Young's modulus of the bar, $\mathrm{E}_{0}=206 \mathrm{GPa}, \rho_{0}$ is density of the bar, $\rho_{0}=7850 \mathrm{~kg} / \mathrm{m}^{3}, 1_{\mathrm{s}}$ is the length of the specimen, $\mathrm{A}_{0}$ and $\mathrm{A}_{\mathrm{s}}$ are the cross-sectional area of the bar and the specimen, respectively. Moreover, $\varepsilon_{\mathrm{I}}(\mathrm{t})$ and $\varepsilon_{\mathrm{T}}(\mathrm{t})$ are strain gauge signals of the incident and transmitted pules, respectively.

\subsection{Experimental Procedure for $S H P B$}

The different strain rates were obtained through adjusting the air pressure from 0.6 to $1.3 \mathrm{MPa}$. In order to reduce the friction between the bars and specimen, some Vaseline lubrication oil was adopted on the ends of bars. Then, the 3D four-step braided composites were imbedded between the incident bar and transmitted bar, ensuring the specimen was centered between the bars to enhance the reliability. The typical strain waves were measured by the stain gauges for the specimen after 210 cyclic hygrothermal aging days, at the strain rate $1845 \mathrm{~s}^{-1}$, which is shown in Figure 6. It can be seen that the incident wave is very close to a square wave, and the amplitude of the incident wave is a function of the impact velocity. The reflected wave represents the strain rate vs. time curve. The reflected wave is oscillating at a certain constant value when the maximum value is reached, which implies that the specimen satisfies the constant strain rate assumption. The stress vs. time curve is presented through the transmitted wave. In order to guarantee the repeatability of the tests, we carried out the repeatable tests. Figure 7 shows the contrast of the stress-strain curves for the specimens of 14 cyclic hygrothermal aging days under the same pressure, $0.6 \mathrm{MPa}$. It can be found that the stress-strain curves are almost identical, and the strain rates were similar, which is done to enhance the repeatability of the tests and to further ensure the reliability of the test data.

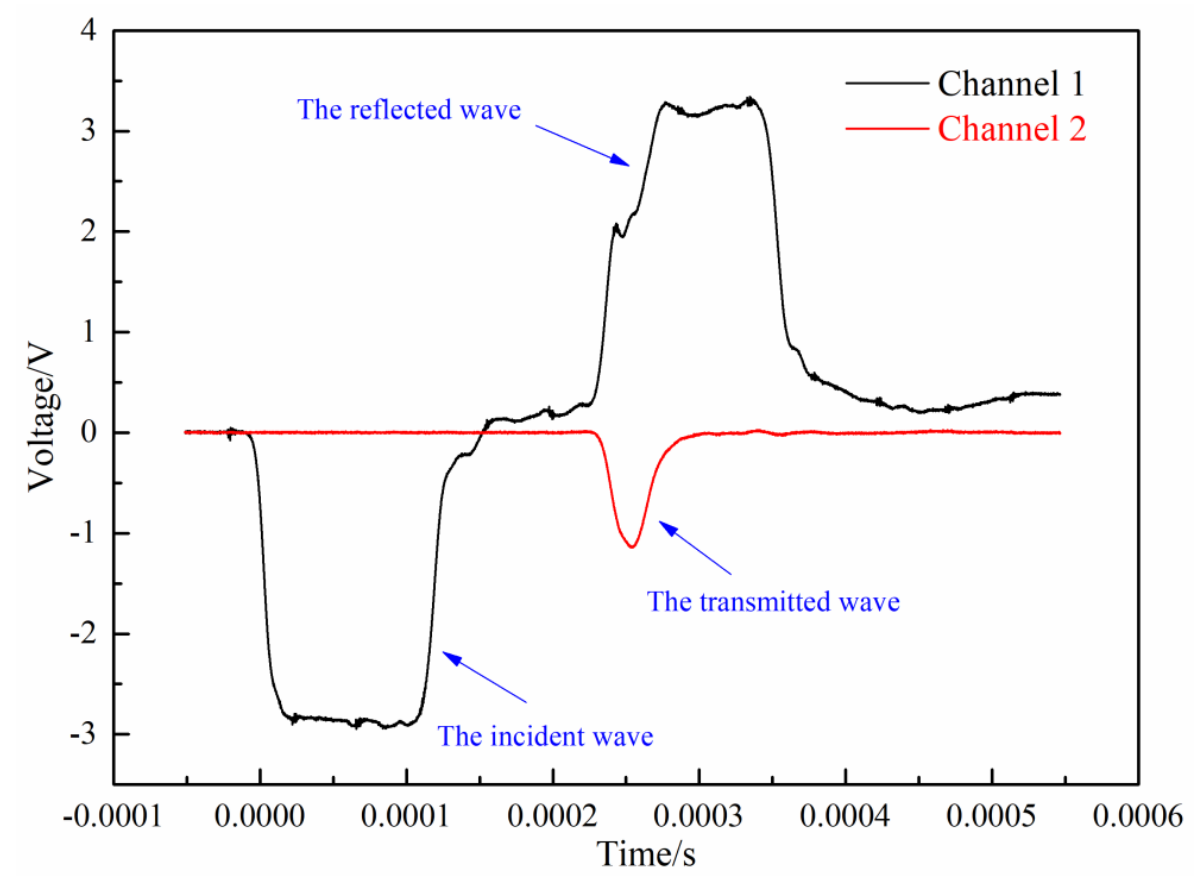

Figure 6. Typical signals on the incident and transmission bars for 210 cyclic hygrothermal aging days under $1845 \mathrm{~s}^{-1}$. 


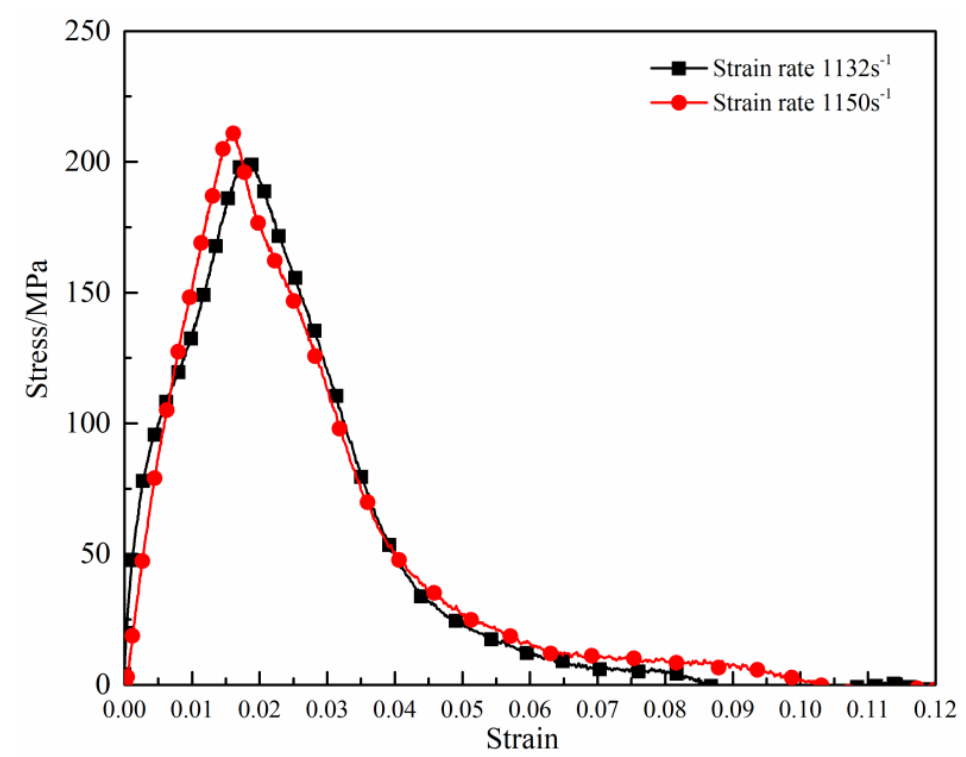

Figure 7. Contrast of the stress-strain curves for the specimens of 14 cyclic hygrothermal aging days under the same pressure $0.6 \mathrm{MPa}$.

Figure 8 shows the strain rate history curves under dynamic loading for specimens after 14,70 , 140, 210 cyclic hygrothermal aging days (abbreviation, HA14, HA70, HA140, HA210, respectively.) under typical strain rate $1700-1800 \mathrm{~s}^{-1}$. It can be found that the curves of the strain rate vs. time under different hygrothermal aging days were similar at the air pressure $1.3 \mathrm{MPa}$ (strain rate 1700-1800 s-1.). In this study, the average values of the plateau region highlighted by dot lines were adopted as strain rates, whose values were shown in corresponding boxes in Figure 8.

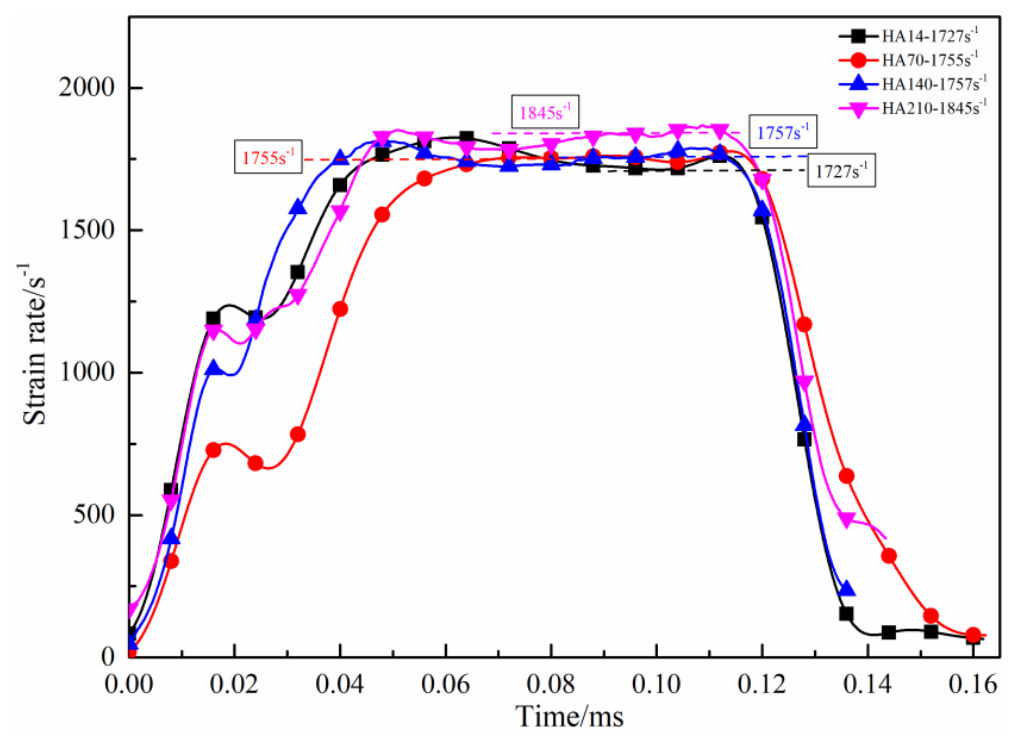

Figure 8. The strain rate history curves under dynamic loading for specimens after 14, 70, 140, 210 hygrothermal aging days under typical strain rate $1700-1800 \mathrm{~s}^{-1}$.

\section{Results and Discussion}

\subsection{Moisture Absorption Behavior}

The water content $M$ defined as:

$$
\mathrm{M}=\frac{\mathrm{W}-\mathrm{W}_{\mathrm{d}}}{\mathrm{W}_{\mathrm{d}}} \times 100 \%
$$


where $W_{d}$ is the weight of the dry specimen and $W$ is the weight of the specimen after hygrothermal aging. The weights and moisture absorption rates of the specimens can be found in Table 1.

Table 1. Moisture absorption parameters of 3D four-step braided composites after different cyclic hygrothermal aging days.

\begin{tabular}{cccc}
\hline Hygrothermal Aging Days & Average Weight $W(g)$ & Standard Deviation & Water Content (\%) \\
\hline 0 & 15.6710 & 0.0320 & 0 \\
14 & 15.7069 & 0.0323 & 0.2288 \\
70 & 15.7267 & 0.0348 & 0.3550 \\
140 & 15.7564 & 0.0344 & 0.5448 \\
210 & 15.7799 & 0.0343 & 0.6944 \\
\hline
\end{tabular}

The 210 days of moisture absorption of 3D four-step braided composite, as a function of square root of time (hour 0.5), is shown in Figure 9, and the moisture absorption of the T700/TDE85 laminated composite after cyclic hygrothermal aging by our previous work [35] was also added into Figure 9, in order to analyze contrastively moisture absorption behavior of 3D four-step braided composites more comprehensively. It can be found that the 3D four-step braided composite did not achieve the saturated moisture absorption, and the relationship between moisture absorption and aging time was almost linear; the maximum moisture absorption was $0.6944 \%$. However, the T700/TDE85 laminated composite not only reached the saturated moisture absorption $(1.261 \%$, at 180 cyclic hygrothermal aging days), but also the maximum moisture absorption (1.261\%) [35], which was almost twice that of the 3D four-step braided composite at the same cyclic hygrothermal aging days. In this study, the magnitude of the diffusion coefficient of the 3D four-step braided composite could not be computed, for the reason that the saturated moisture absorption was not reached under 210 cyclic hygrothermal aging days, according to the Fick law. The reason that the saturation moisture absorption of 3D four-step braided composites was not reached during this study, is that its spatial structure is more sophisticated, which may cause more porosity of the matrices that may act as secondary absorption locations and lead to deviations from the Fick diffusion behavior [38,39] compared with the laminated composites.

It is well recognized that the diffusion mechanism of water molecules with the polymer composites is obviously different from that in a pure polymer, because the interfaces between fibers and resin play a decisive role in the whole moisture absorption. The moisture absorption process of the composites mainly contains three phases: epoxy plasticization, epoxy hydrolysis and interfaces debonding (causing cracks). At the beginning, the water entered into the specimen from the specimen surface, then the water molecules diffused into the resin through microflaws (e.g., void or microcracks). With the absorption process of water molecules continuing, the epoxy had produced plasticization, this is because the weak interactions between water molecules and polymer chains inside epoxy ranged from Van der Waals bonds into single hydrogen bonds. In addition, the water molecules which entered into epoxy acted as a corrosion agent and promoted epoxy hydrolysis. The volume of epoxy increased with the increased polymer chain mobility and disruption of interchain Van der Waals, which produced differential swelling stresses (since the carbon fibers do not absorb water), that might drive the interfaces debonding between fiber and epoxy [18,40,41].

Figure 10 presents the damage evolution on the cross section of the 3D four-step composites after different hygrothermal aging days. Some broken fibers were observed on the surface of the composite, due to defects caused during the manufacturing process, as shown (Figure 10a). Before hygrothermal aging, the surface of epoxy was relatively smooth, except that there were some impurities. After 14 cyclic hygrothermal aging days, some potholes appeared on the surface of epoxy, with a length below $100 \mu \mathrm{m}$, which was the phenomenon after epoxy hydrolysis. During water absorption, both free and bound water molecules existed in the epoxy network, based on the formation of either one or two hydrogen bonds with polymer chains [42]. Two types between water molecules and polymeric chains are shown in Figure 11. The black lines stand for the backbone chains of epoxy, and the water 
molecules are represented in red color. Figure 11a,b explain the case of one hydrogen bond for water molecules, and two hydrogen bonds, respectively. Continuing hygrothermal aging days, some fibers were exposed when the area and depth of epoxy hydrolysis increased, as shown in Figure 10c. Later on in the cyclic hygrothermal aging days, the cracks in both Figure 10d,e can be found, and the cracks were on the junction of the braiding yarns and epoxy; differential swelling stresses can be employed to explain the phenomenon. The combined effects of epoxy plasticization, epoxy hydrolysis and cracks caused by interfaces debonding, contribute to a change in dynamic mechanical performance after cyclic hygrothermal aging.

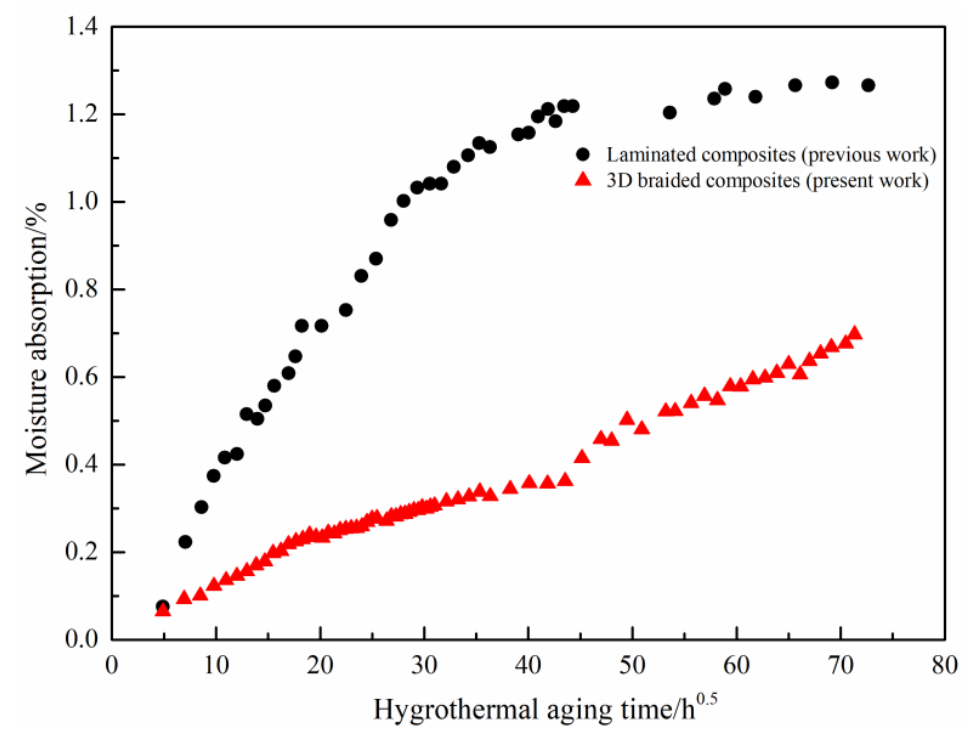

Figure 9. Contrast of moisture absorption between the 3D four-step braided composites and the T700/TDE85 laminated composites during 210 cyclic hygrothermal aging days.

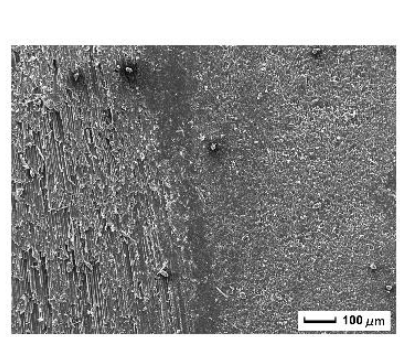

(a) 0 day

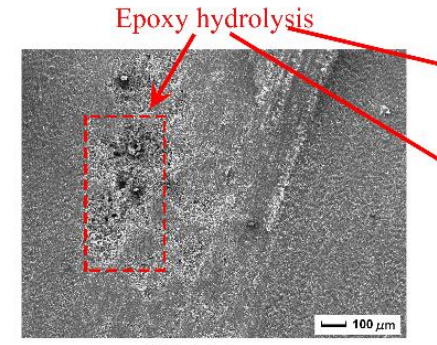

(b) 14 days

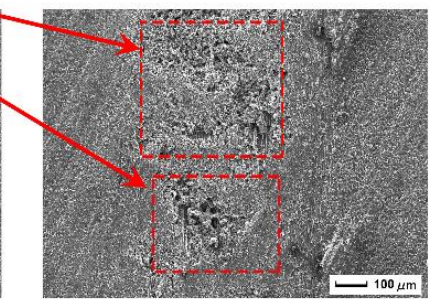

(c) 70 days

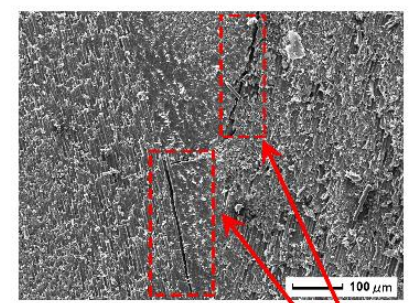

(d) 140 days

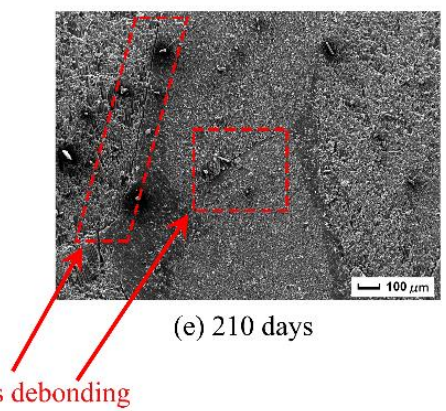

Figure 10. Damage evolution on the cross section of the 3D four-step braided composites after different cyclic hygrothermal aging days, (a) 0 day, (b) 14 days, (c) 70 days, (d) 140 days, (e) 210 days. 


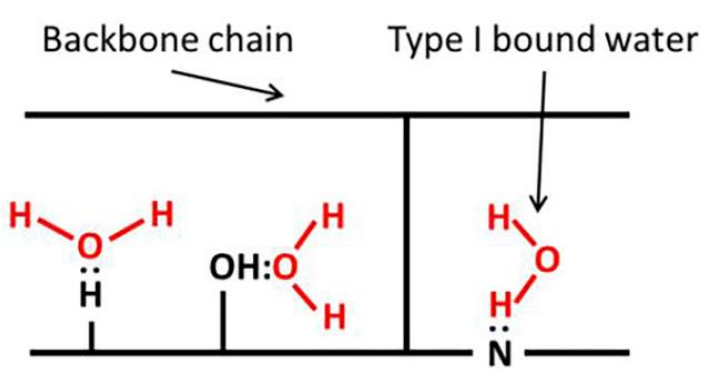

(a)
Type II bound water

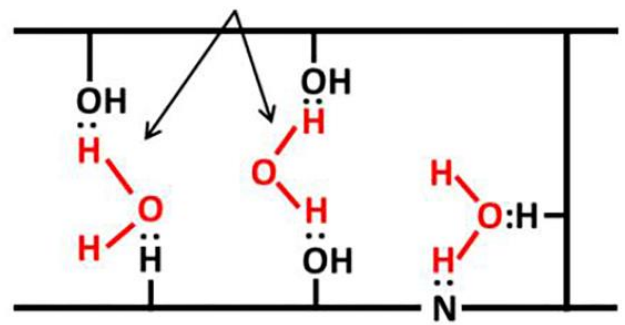

(b)

Figure 11. Two types between water molecules and polymeric chains, (a) Type I bound water forming one hydrogen bond, (b) Type II bound water forming two hydrogen bonds [42].

\subsection{Typical Dynamic Compressive Process for Braided Composites Captured by High-Speed Camera}

Figure 12 shows the typical dynamical compressive process under strain rate $1845 \mathrm{~s}^{-1}$, after 210 cyclic hygrothermal aging days. From this figure, it can be seen that the 3D four-step braided composite mainly experienced matrix failure, braiding yarns kinking and finally disassembling when subjected to compression along the longitudinal direction. When the incident bar impacted the specimen, the surface of the specimen no longer remained intact and some surface braiding yarns [43] kinked, due to matrix failure under compressive stress wave propagation. At $0.1 \mathrm{~ms}$, all surface braiding yarns kinked, the matrix could no longer maintain structural integrity of the 3D four-step braided composite, and the composite entered the phase of composite disassembly. From $0.125 \mathrm{~ms}$, the braiding yarns struggled to get rid of the constraints of the matrix, and during this process, matrix failure was the most damaged mode, and the fibers in braiding yarns had almost no damage.
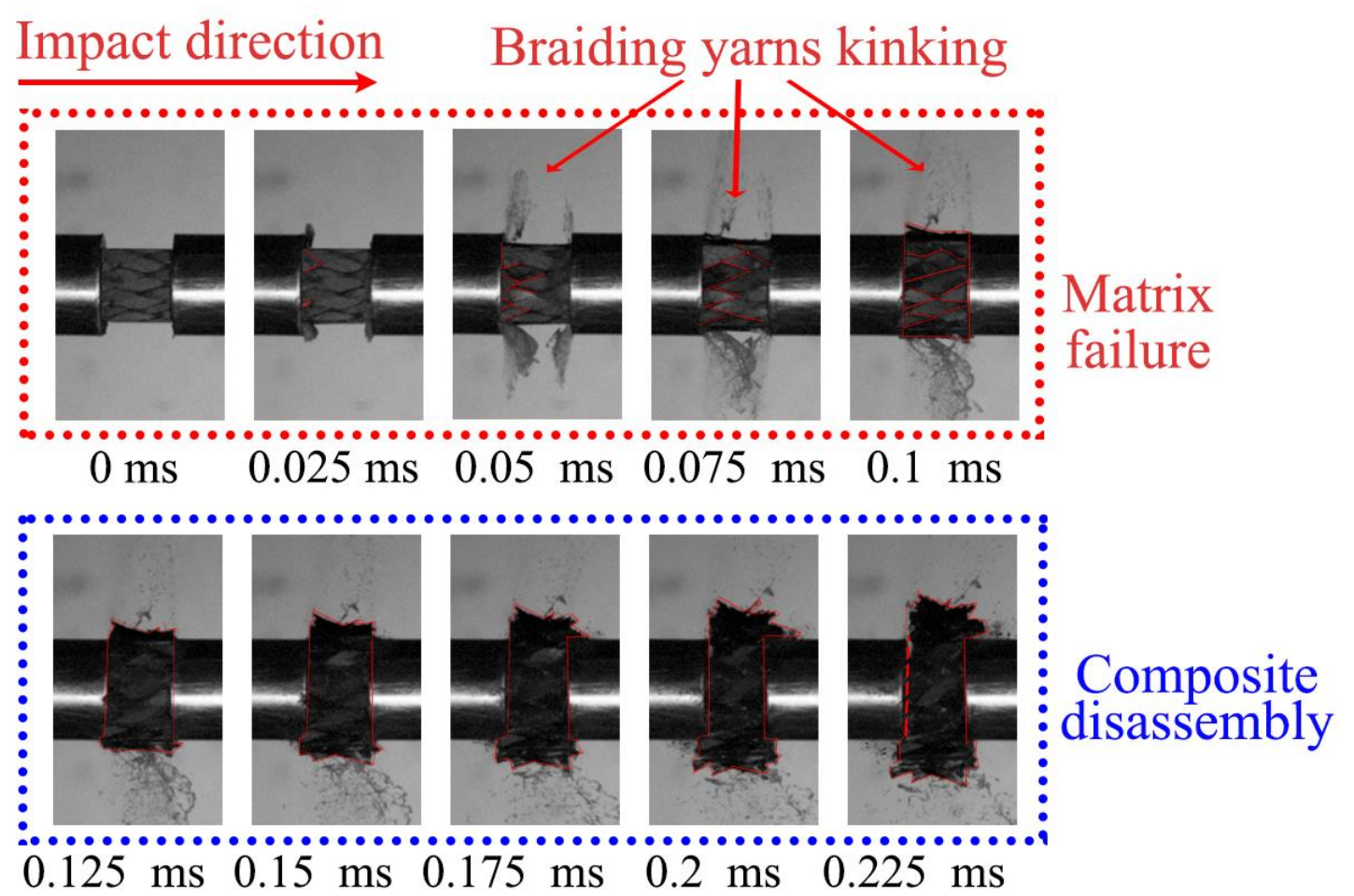

Figure 12. Typical dynamical compressive process for the 3D four-step braided composite under strain rate $1845 \mathrm{~s}^{-1}$, after 210 cyclic hygrothermal aging days.

Figure 13 gives the typical fracture morphology for the 3D four-step braided composite under strain rate $1845 \mathrm{~s}^{-1}$ after 210 cyclic hygrothermal aging days. It can be found that the matrix failure was 
the main damage mode when the specimens were subjected to impact in the longitudinal direction. The yarns were scarcely damaged at the macro level. It is important to emphasize that the specimens for the SHPB tests were cut from the whole braided composite plate, which could decrease the strength and stiffness of the 3D braided composites due to the cut-edge effect. This may be also the reason that the specimens broken up when subjected to the longitudinal compression under high strain rates. There is no difference in the fracture morphology for the 3D braided composites between un-hygrothermal aging and hygrothermal aging, compared to our previous work [15].

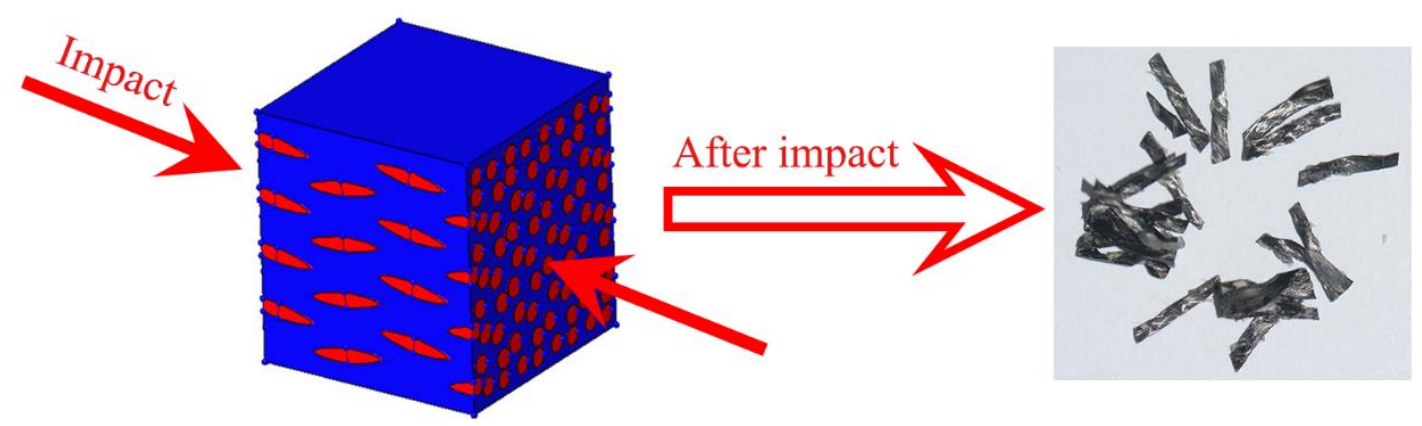

Figure 13. The typical fracture morphology for the 3D four-step braided composite under strain rate $1845 \mathrm{~s}^{-1}$ after 210 cyclic hygrothermal aging days.

\subsection{Dynamic Mechanical Properties for Braided Composites with Different Hygrothermal Aging Days}

Figure 14 shows the dynamic compressive stress vs. strain curves for different hygrothermal aging days. All stress strain curves, whether hygrothermaling aging or not, reveal that the 3D four-step braided composites almost behave in a linear response in the initial stage and have no significant yield in the impact process. However, the composites had non-linear behavior at the location close to the peak stress, and then the stress declined gradually beyond the peak stress. This is because the degradation of the matrix and debonding between yarns and the epoxy increase gradually, which exhibits a progressive loss of stiffness. It is worth noting that a plateau appears near the peak stress at the HA70 specimen under $1755 \mathrm{~s}^{-1}$, which meant that the stiffness loss of the HA70 specimen was progressive before the peak stress. The reason that this occurred is that the epoxy in the specimen endured plasticization, that enhanced the stiffness to a certain extent. Combined with Figure 15a, it can be found that with increasing strain rate, the peak stress shows a significant strain rate effect at different hygrothermal aging days. However, there is no obvious trend in the dynamic stiffness modulus, and no remarkable strain rate effect after hygrothermal aging in Figure 15b. From the above, we conclude that the peak stress of the 3D four-step braided composite is still sensitive after cyclic hygrothermal aging, when compressed in the longitudinal direction at high strain rates.

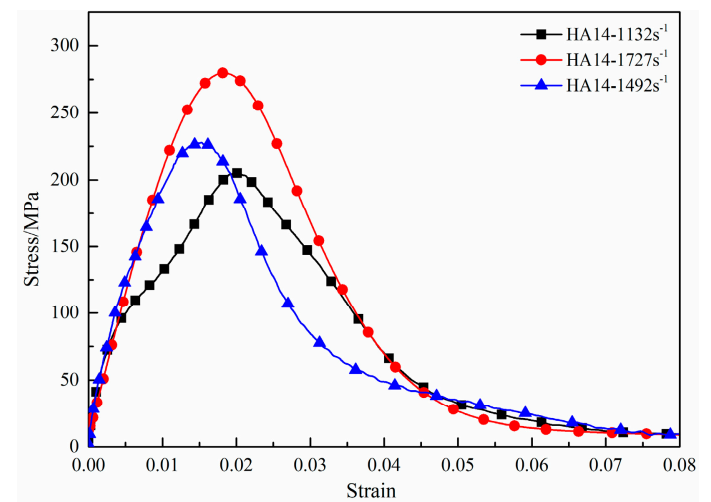

(a) 14 days

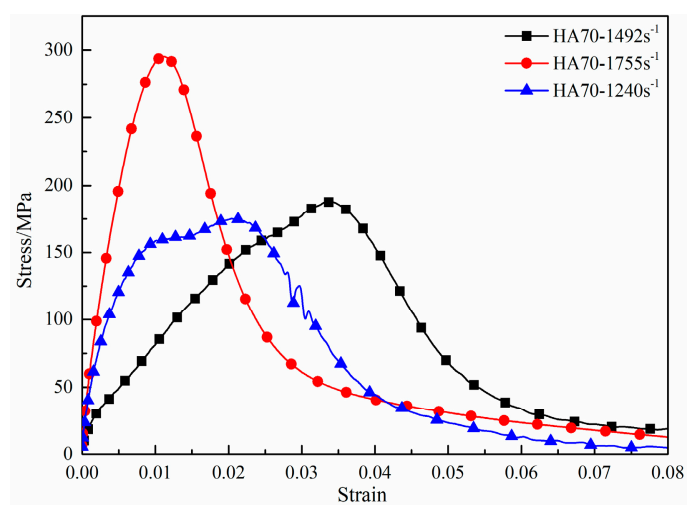

(b) 70 days

Figure 14. Cont. 


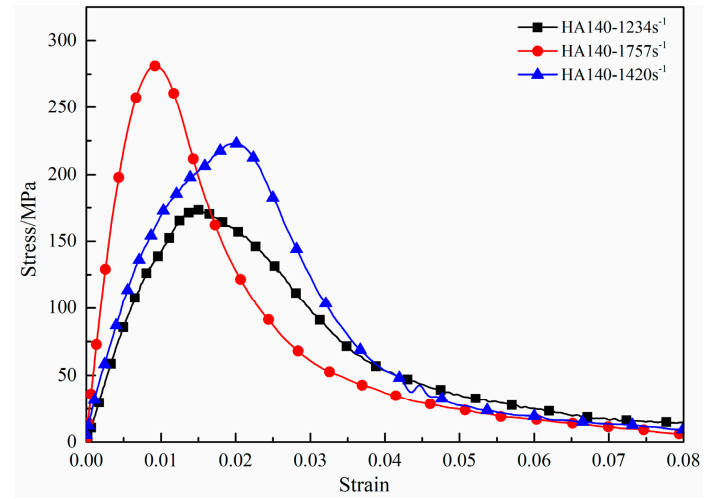

(c) 140 days

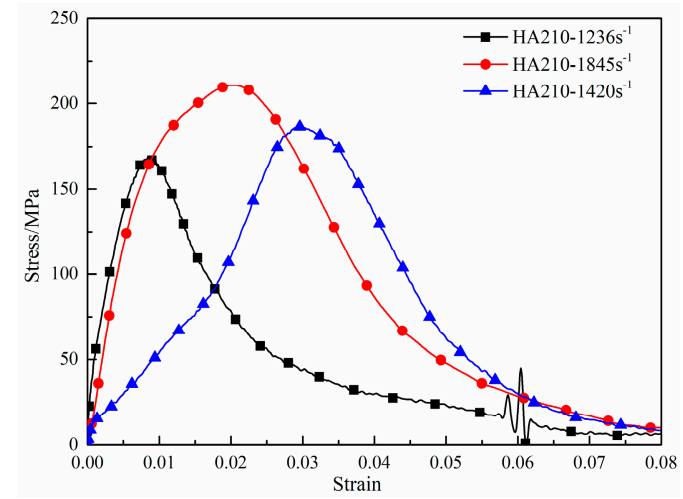

(d) 210 days

Figure 14. Dynamic compressive stress vs. strain curves for the 3D four-step braided composites after different hygrothermal aging days, (a) 14 days, (b) 70 days, (c) 140 days, (d) 210 days.

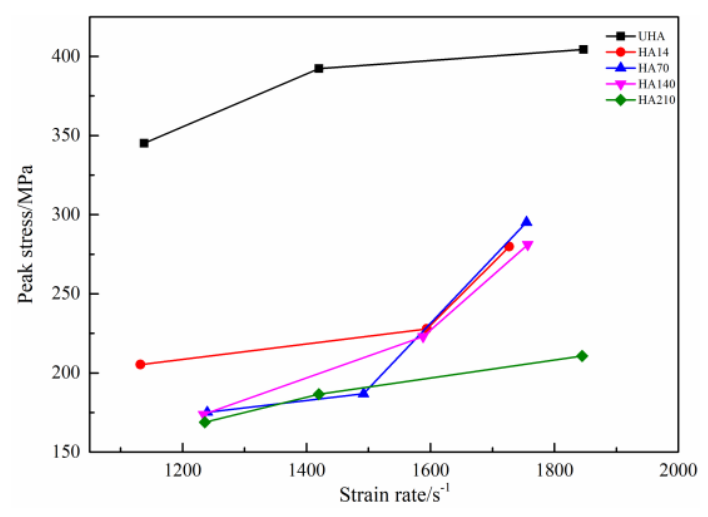

(a) peak stress vs. strain rate

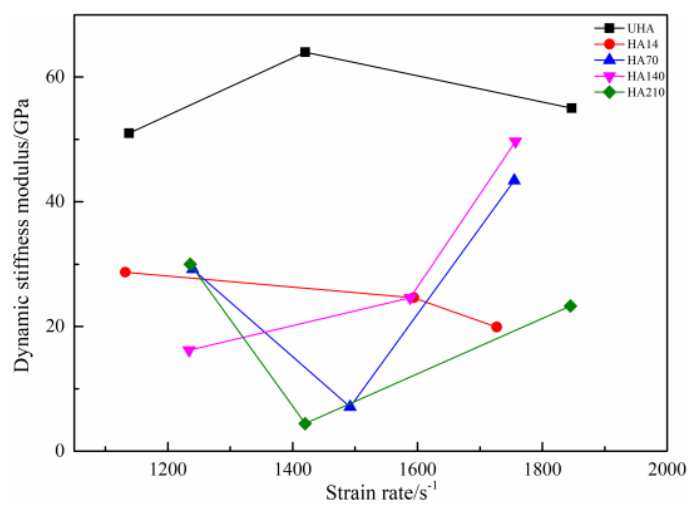

(b) dynamic stiffness modulus vs. strain rate

Figure 15. Dynamic mechanical property vs. strain rate for the 3D four-step braided composites under different hygrothermal aging days, (a) peak stress vs. strain rate, (b) dynamic stiffness modulus vs. strain rate.

\subsection{Hygrothermal Aging Effects for Braided Composites under High Strain Rates}

In order to evaluate the hygrothermal aging effects of 3D four-step braided composites when compressed on the longitudinal direction under high strain rates, in this study, the difference of dynamic mechanical properties of the composites between hygrothermal aging and un-hygrothermal aging (abbreviation, UHA) at three high strain rates that correspond to 1100 1250 s $\mathrm{s}^{-1}, 1400 \sim 1600 \mathrm{~s}^{-1}$, $1700 \sim 1850 \mathrm{~s}^{-1}$, respectively. Due to the limit on the number of the specimens, the dynamic experimental results of the un-hygrothermal aging specimens are from our previous work [15]. However, the previous work lacked the experimental results under the strain rate $1400 \sim 1600 \mathrm{~s}^{-1}$, therefore, we did the SHPB tests of un-hygrothermal aging specimens under strain rate 1400 1600 s ${ }^{-1}$. It is important to emphasize that all specimens, whether they are the specimens in our previous work [15] or the specimens in this study, came from the same batch of 3D four-step braided composites. The validity and objectivity of the experimental tests can be guaranteed this way. Figures 16a, 17a and 18a present the stress vs. strain curves of the composites between hygrothermal aging and un-hygrothermal aging under three high strain rates. The stress vs. strain curves of un-hygrothermal aging specimens also present in a linear manner up to failure and have no clear yield at three high strain rates. The peak stresses are $345.1 \mathrm{MPa}, 392.3 \mathrm{MPa}$, and $404.4 \mathrm{MPa}$, corresponding to the strain rates $1138 \mathrm{~s}^{-1}$, $1420 \mathrm{~s}^{-1}$, and $1847 \mathrm{~s}^{-1}$, respectively. The peak stress of 3D four-step braided composites without hygrothermal aging also behaves like the strain rate effect. It reveals that the experimental result of the un-hygrothermal aging specimen under the strain rate $1420 \mathrm{~s}^{-1}$ in this study is in accordance with 
the conclusion that peak stress has a strain rate effect in our previous work [15]. At the same time, it can obviously be seen that the peak stress and the dynamic stiffness modulus of un-hygrothermal aging specimens are both greater than that hygrothermal aging specimen. It can be concluded that the dynamic compressive strength in a longitudinal direction was weakened when subjected to cyclic hygrothermal aging. Figure 16b,c, Figure 17b,c and Figure 18b,c shows the effects of hygrothermal aging on the peak stress and dynamic stiffness modulus. It can be seen that no matter the peak stress or the dynamic stiffness, the moduli have both decreased significantly after cyclic hygrothermal aging. However, the peak stress and dynamic stiffness modulus have not shown any specific regularity from 14 to 210 cyclic hygrothermal aging days at three high strain rates. Although the peak stress of the specimens under strain rate 1100 1250 s ${ }^{-1}$ decreases with respect to the increase of cyclic hygrothermal aging days, the same value shows no obvious up or down trend with the increase of cyclic hygrothermal aging days under strain rate 1400 1600 s ${ }^{-1}$ and 1700 1850 s${ }^{-1}$. In particular, the peak stress and the dynamic stiffness modulus reached a minimum value at 210 cyclic hygrothermal aging days, under three high strain rates. The peak stress decreased by $51.06 \%, 52.43 \%, 47.90 \%$, compared with that without hygrothermal aging under the strain rate 1100 1250 s $\mathrm{s}^{-1}, 1400 \sim 1600 \mathrm{~s}^{-1}, 1700 \sim 1850 \mathrm{~s}^{-1}$, respectively. The dynamic stiffness modulus decreased by $41.18 \%, 93.13 \%, 58.02 \%$ compared with that without hygrothermal aging under the strain rates 1100 1250 s${ }^{-1}, 1400 \sim 1600 \mathrm{~s}^{-1}$, and 1700 1850 s${ }^{-1}$, respectively. All of these results demonstrate that the peak stress and the dynamic stiffness modulus of 3D four-step braided composites after 210 cyclic hygrothermal aging days almost decrease by half when subjected to longitudinal compression.

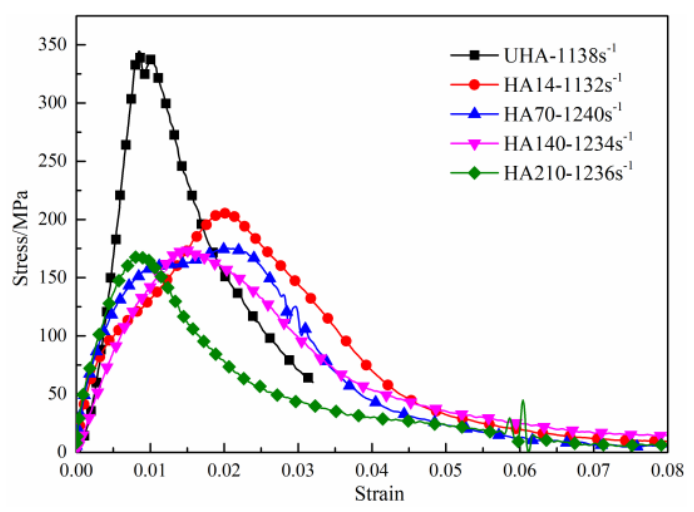

(a) Stress strain curves

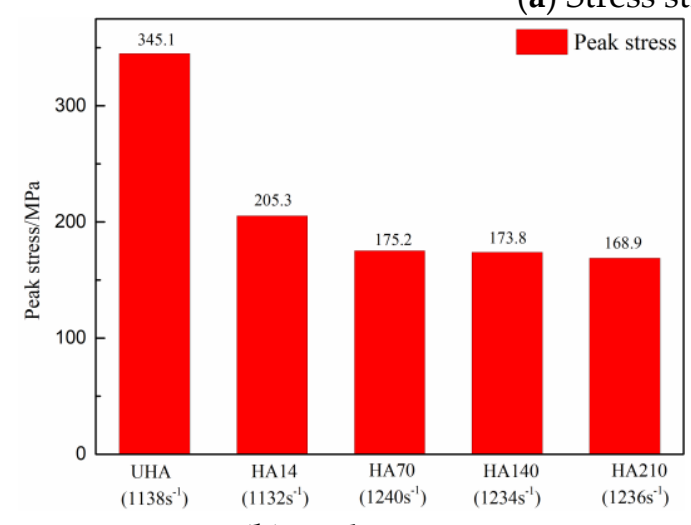

(b) Peak stress

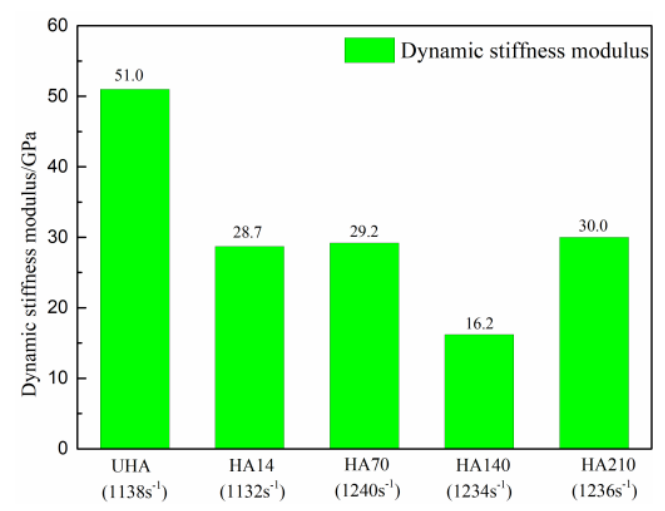

(c) Dynamic stiffness modulus

Figure 16. The effect of cyclic hygrothermal aging on the dynamic compressive properties under $1100 \sim 1250 \mathrm{~s}^{-1}$, (a) Stress strain curves, (b) Peak stress, (c) Dynamic stiffness modulus. 


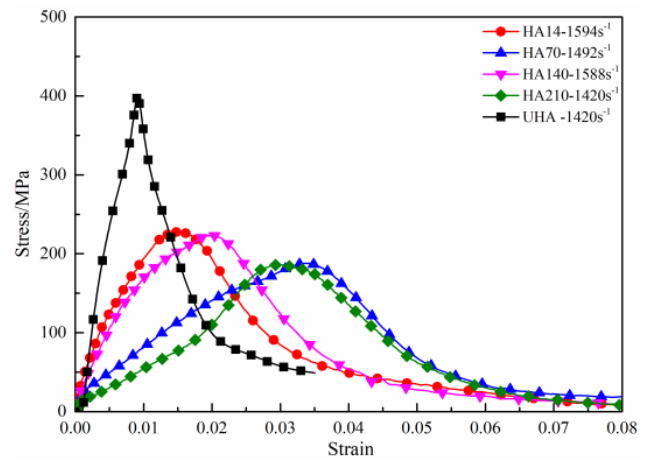

(a) Stress strain curves

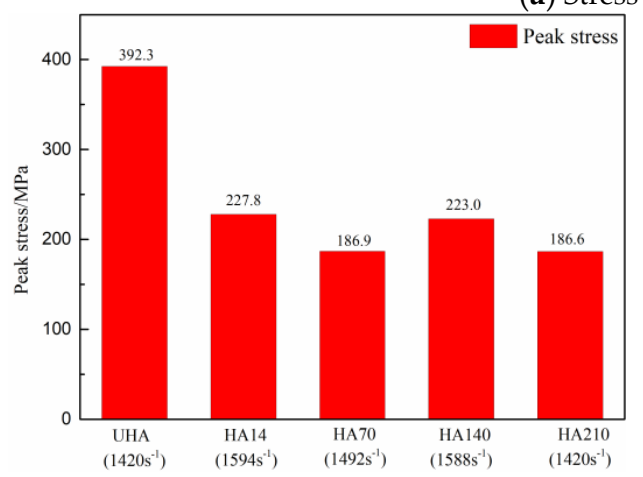

(b) Peak stress

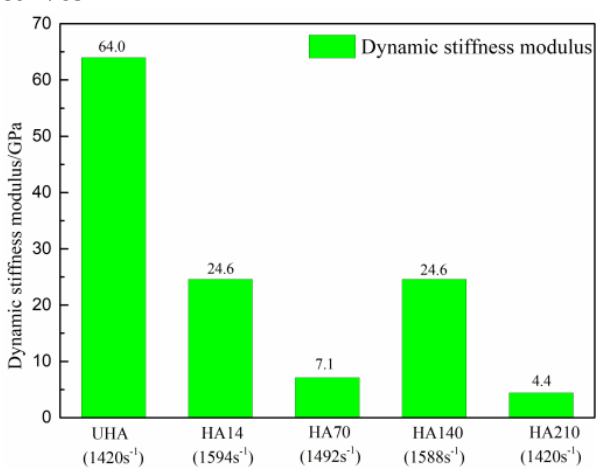

(c) Dynamic stiffness modulus

Figure 17. The effect of cyclic hygrothermal aging on the dynamic compressive properties under $1400 \sim 1600 \mathrm{~s}^{-1}$, (a) Stress strain curves, (b) Peak stress, (c) Dynamic stiffness modulus.

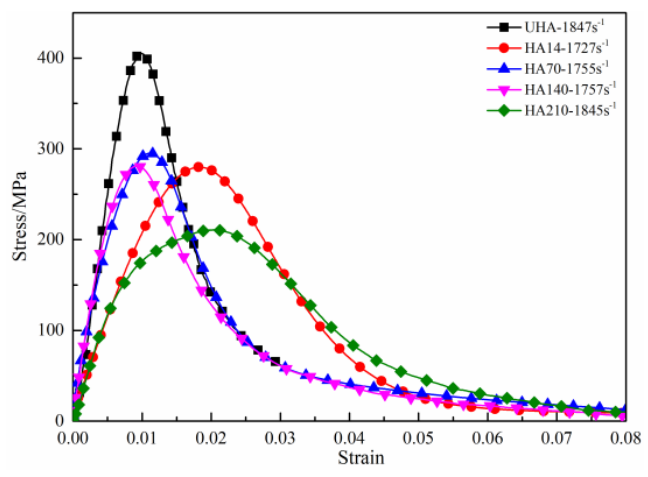

(a) Stress strain curves

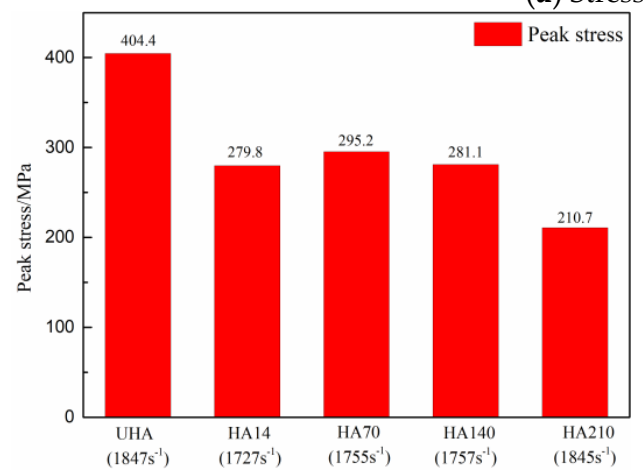

(b) Peak stress

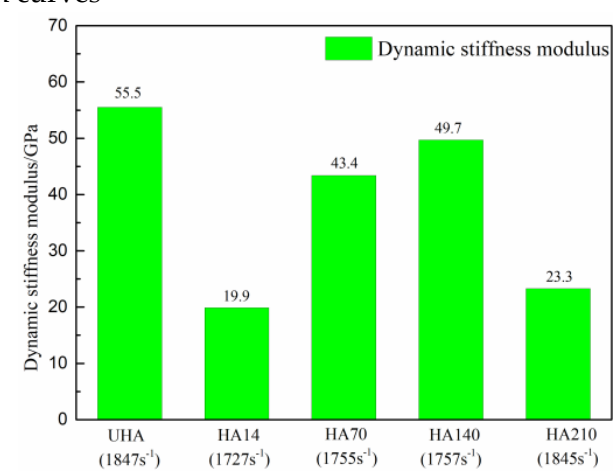

(c) Dynamic stiffness modulus

Figure 18. The effect of cyclic hygrothermal aging on the dynamic compressive properties under $1700 \sim 1850 \mathrm{~s}^{-1}$, (a) Stress strain curves, (b) Peak stress, (c) Dynamic stiffness modulus. 


\section{Conclusions}

In this study, the 3D four-step braided composites were aged in a cyclic hygrothermal environment, and the microscopic damage morphologies of the composites were examined by SEM, to determine the damage evolution with cyclic hygrothermal aging days. A split Hopkinson pressure bar (SHPB) apparatus was employed, to determine the dynamic mechanical properties of the composites under three high strain rates, when subjected to the longitudinal compression. The main findings are summarized in the following:

(1) The saturated moisture absorption of 3D four-step braided composites was not reached over the full duration of 210 cyclic hygrothermal aging days, the maximum moisture absorption was $0.6944 \%$, and the composites did not show very much non-linear moisture behavior, compared with the T700/TDE85 laminated composites in our previous work.

(2) The damage evolution of 3D four-step composites during the whole cyclic hygrothermal aging days mainly included epoxy hydrolysis and interfaces debonding.

(3) The dynamic compressive stress-strain curves for the 3D four-step braided composites both behaved in a similar way, whether cyclic hygrothermal aging or not, and a linear response in the initial stage had no significant yield before reaching the peak stress.

(4) The peak stress of the 3D four-step braided composites still behaved as a strain rate effect after cyclic hygrothermal aging, however, the dynamic stiffness modulus clearly had no specific regularity.

(5) The peak stress and the dynamic stiffness modulus of 3D four-step braided composites after 210 cyclic hygrothermal aging days almost decreased by half when subjected to longitudinal compression.

Author Contributions: Conceptualization, L.L.; methodology, K.X. and W.C.; software, K.X.; validation, K.X., G.L. and Z.Z.; formal analysis, K.X.; investigation, K.X. and L.L.; resources, L.L.; data curation, K.X., G.L. and Z.Z.; writing —original draft preparation, K.X.; writing-review and editing, W.C. and L.L.; visualization, K.X.; supervision, W.C.; project administration, L.L.; funding acquisition, L.L. and W.C. All authors have read and agreed to the published version of the manuscript.

Funding: This research was funded by the National Natural Science Foundation of China (Grant No. 51975279, and 51605218) and Equipment Pre-research field Foundation of Equipment Development Department of China (61409220203).

Acknowledgments: The authors would like to thank Chunbo Wu for his suggestions about image processing.

Conflicts of Interest: The authors declare no conflict of interest.

\section{References}

1. Schultheisz, C.R.; Waas, A.M. Compressive failure of composites, Part I: Testing and micromechanical theories. Prog. Aerosp. Sci. 1996, 32, 1-42. [CrossRef]

2. Wang, H.; Hazell, P.J.; Shankar, K.; Morozov, E.V.; Escobedo, J.P. Impact behaviour of Dyneema ${ }^{\circledR}$ fabric-reinforced composites with different resin matrices. Polym. Test. 2017, 61, 17-26. [CrossRef]

3. Li, Z.; Khennane, A.; Hazell, P.J.; Remennikov, A.M. Performance of a hybrid GFRP-concrete beam subject to low-velocity impacts. Compos. Struct. 2018, 206, 425-438. [CrossRef]

4. Huang, H.J.; Waas, A.M. Modeling and predicting the compression strength limiting mechanisms in Z-pinned textile composites. Compos. Part B Eng. 2009, 40, 530-539. [CrossRef]

5. Pankow, M.; Waas, A.M.; Yen, C.F.; Ghiorse, S. Shock loading of 3D woven composites: A validated finite element investigation. Compos. Struct. 2011, 93, 1347-1362. [CrossRef]

6. Zhang, D.; Waas, A.M.; Yen, C.F. Progressive damage and failure response of hybrid 3D textile composites subjected to flexural loading, part I: Experimental studies. Int. J. Solids Struct. 2015, 75-76, 309-320. [CrossRef]

7. Xuan, H.J.; Wu, R.R. Aeroengine turbine blade containment tests using high-speed rotor spin testing facility. Aerosp. Sci. Technol. 2006, 10, 501-508. [CrossRef]

8. Guan, Y.P.; Zhao, Z.H.; Chen, W.; Gao, D.P. Foreign object damage to fan rotor blades of aeroengine part I: Experimental study of bird impact. Chin. J. Aeronaut. 2008, 21, 328-334. 
9. Gu, B.H.; Xu, J.Y. Finite element calculation of 4-step 3-dimensional braided composite under ballistic perforation. Compos. Part B Eng. 2004, 35, 291-297. [CrossRef]

10. Sun, B.Z.; Liu, F.; Gu, B.H. Influence of the strain rate on the uniaxial tensile behavior of 4-step 3D braided composites. Compos. Part A Appl. Sci. Manuf. 2005, 36, 1485. [CrossRef]

11. Sun, B.Z.; Gu, B.H. High strain rate behavior of 4-step 3D braided composites under compressive failure. J. Mater. Sci. 2007, 42, 2463-2470. [CrossRef]

12. Sun, B.Z.; Gu, B.H. In-plane compressive behaviors of 3-D textile composites at various strain rates. Appl. Compos. Mater. 2007, 14, 193-207. [CrossRef]

13. Walter, T.R.; Subhash, G.; Sankar, B.V.; Yen, C.F. Damage modes in 3D glass fiber epoxy woven composites under high rate of impact loading. Compos. Part B Eng. 2009, 40, 584-589. [CrossRef]

14. Zhang, F.; Wan, Y.; Gu, B.H.; Sun, B.Z. Impact compressive behavior and failure modes of four-step three-dimensional braided composites-based meso-structure model. Int. J. Damage Mech. 2015, 24, 805-827. [CrossRef]

15. Tan, H.C.; Huang, X.; Liu, L.L.; Guan, Y.P.; Chen, W. Dynamic compressive behavior of four-step three-dimensional braided composites along three directions. Int. J. Impact Eng. 2019, 134, 103366. [CrossRef]

16. Diamant, Y.; Marom, G.; Broutman, L.J. The effect of network structure on moisture absorption of epoxy resins. J. Appl. Polym. Sci. 1981, 26, 3015-3025. [CrossRef]

17. Davies, P.; Mazéas, F.; Casari, P. Sea water aging of glass reinforced composites: Shear behaviour and damage modelling. J. Compos. Mater. 2001, 35, 1343-1372. [CrossRef]

18. Joliff, Y.; Rekik, W.; Belec, L.; Chailan, J.F. Study of the moisture/stress effects on glass fibre/epoxy composite and the impact of the interphase area. Compos. Struct. 2014, 108, 876-885. [CrossRef]

19. Abdel, M.B.; Ziaee, S.; Gass, K.; Schneider, M. The combined effects of load, moisture and temperature on the properties of E-glass/epoxy composites. Compos. Struct. 2005, 71, 320-326. [CrossRef]

20. Tsenoglou, C.J.; Pavlidou, S.; Papaspyrides, C.D. Evaluation of interfacial relaxation due to water absorption in fiber-polymer composites. Compos. Sci. Technol. 2006, 66, 2855-2864. [CrossRef]

21. Ogi, K. Influence of thermal history on transverse cracking in a carbon fiber reinforced epoxy composite. Adv. Compos. Mater. 2003, 11, 265-275. [CrossRef]

22. Zhang, A.; Lu, H.; Zhang, D. Effects of voids on residual tensile strength after impact of hygrothermal conditioned CFRP laminates. Compos. Struct. 2013, 95, 322-327. [CrossRef]

23. Yilmaz, T.; Sinmazcelik, T. Effects of hydrothermal aging on glass-fiber/polyetherimide (PEI) composites. J. Mater. Sci. 2010, 45, 399-404. [CrossRef]

24. Sun, P.; Zhao, Y.; Luo, Y.; Sun, L. Effect of temperature and cyclic hygrothermal aging on the interlaminar shear strength of carbon fiber/bismaleimide (BMI) composite. Mater. Des. 2011, 32, 4341-4347. [CrossRef]

25. Li, G.; Pang, S.S.; Helms, J.E.; Ibekwe, S.I. Low velocity impact response of GFRP laminates subjected to cycling moistures. Polym. Compos. 2000, 21, 686-695. [CrossRef]

26. Liotier, P.J.; Vautrin, A.; Beraud, J.M. Microcracking of composites reinforced by stitched multiaxials subjected to cyclical hygrothermal loadings. Compos. Part A Appl. Sci. Manuf. 2011, 42, 425-437. [CrossRef]

27. Mikhaluk, D.S.; Truong, T.C.; Borovkov, A.I.; Lomov, S.V.; Verpoest, I. Experimental observations and finite element modelling of damage initiation and evolution in carbon/epoxy non-crimp fabric composites. Eng. Fract. Mech. 2008, 75, 2751-2766. [CrossRef]

28. Patel, S.R.; Case, S.W. Durability of hygrothermally aged graphite/epoxy woven composite under combined hygrothermal conditions. Int. J. Fatigue 2002, 24, 1295-1301. [CrossRef]

29. Liu, L.L.; Zhao, Z.Z.; Chen, W.; Shuang, C.; Luo, G. An experimental investigation on high velocity impact behavior of hygrothermal aged CFRP composites. Compos. Struct. 2018, 204, 645-657. [CrossRef]

30. Zhang, M.; Zuo, C.; Sun, B.Z.; Gu, B.H. Thermal ageing degradation mechanisms on compressive behavior of 3-D braided composites in experimental and numerical study. Compos. Struct. 2016, 140, 180-191. [CrossRef]

31. Song, L.; Li, J. Effects of heat accelerated aging on tensile strength of three dimensional braided/epoxy resin composites. Polym. Compos. 2012, 3, 1635-1643.

32. ASTM Standard. ASTM D 5229-29M-Standard Test Method for Moisture Absorption Properties and Equilibrium Conditioning of Polymer Matrix Composite Materials; Annual Book of ASTM Standards; ASTM International: West Conshohocken, PA, USA, 2010. [CrossRef] 
33. De Sarmot, G.; Salvia, M.; Vautrin, A.; Colombaro, A.M. Influence of long term maintenance on the performances of composites for Super Sonic Transportation. In Proceedings of the First National Colloquium of Aeronautic Researches on the Supersonic Aircraft, Paris, France, 6-7 February 2002.

34. Li, Y.; Chen, Y.; Sheng, G.; Li, G. Hygrothermal aging effects for aircraft composite structures. In Proceedings of the 11th National Conference on Composite Materials, Hefei, China, 21-25 October 2000. (In Chinese).

35. Liu, L.L.; Zhao, Z.Z.; Chen, W.; Xue, M.F.; Shuang, C. Interlaminar shear property and high-velocity impact resistance of CFRP laminates after cyclic hygrothermal aging. Int. J. Crashworthiness 2019, 1-14. [CrossRef]

36. Kolsky, H. An investigation of the mechanical properties of materials at very high rates of loading. Proc. Phys. Soc. Sect. B 1949, 62, 676-700.

37. Gama, B.A.; Lopatnikov, S.L.; Gillespie, J.W. Hopkinson bar experimental technique: A critical review. Appl. Mech. Rev. 2004, 57, 223-250. [CrossRef]

38. Kumosa, L.; Benedikt, B.; Armentrout, D.; Kumosa, M. Moisture absorption properties of unidirectional glass/polymer composites used in composite (non-ceramic) insulators. Compos. Part A Appl. Sci. Manuf. 2004, 35, 1049-1063. [CrossRef]

39. Gautier, L.; Mortaigne, B.; Bellenger, V. Interface damage study of hydrothermally aged glass-fibre-reinforced polyester composites. Compos. Sci. Technol. 1999, 59, 2329-2337.

40. Gagani, A.I.; Echtermeyer, A.T. Fluid diffusion in cracked composite laminates-Analytical, numerical and experimental study. Compos. Sci. Technol. 2018, 160, 86-96. [CrossRef]

41. Morii, T.; Ikuta, N.; Kiyosumi, K.; Hamada, H. Weight-change analysis of the interphase in hygrothermally aged FRP: Consideration of debonding. Compos. Sci. Technol. 1997, 57, 985-990. [CrossRef]

42. Zhou, J.; Lucas, J.P. Hygrothermal effects of epoxy resin. Part I: The nature of water in epoxy. Polymer 1999, 40, 5505-5512. [CrossRef]

43. Tan, H.C.; Liu, L.L.; Guan, Y.P.; Chen, W.; Zhao, Z.Z. Investigation of three-dimensional braided composites subjected to steel projectile impact: Automatically modelling mesoscale finite element model. Compos. Struct. 2019, 209, 317-327.

(C) 2020 by the authors. Licensee MDPI, Basel, Switzerland. This article is an open access article distributed under the terms and conditions of the Creative Commons Attribution (CC BY) license (http://creativecommons.org/licenses/by/4.0/). 